\title{
Prevalence of vulvovaginal candidiasis in females in the reproductive age group
}

\author{
Meena Salvi* \\ Department of Obstetrics and Gynecology, Prime Medical Centre, Sharjah attached with Prime Hospital, Dubai, U.A.E
}

Received: 17 November 2018

Accepted: 29 December 2018

\section{*Correspondence:}

Dr. Meena Salvi,

E-mail: meenabhati2007@gmail.com

Copyright: $\odot$ the author(s), publisher and licensee Medip Academy. This is an open-access article distributed under the terms of the Creative Commons Attribution Non-Commercial License, which permits unrestricted non-commercial use, distribution, and reproduction in any medium, provided the original work is properly cited.

\begin{abstract}
Background: Vulvovaginal candidiasis (VVC) is a common infection among reproductive age group females. The objective of present study is to determine the prevalence of vulvovaginal candidiasis, its distribution and association of risk factors among reproductive age group females, attending the outpatient department of obstetrics and gynaecology of our Prime Medical Centre, Sharjah attached with Prime Hospital, Dubai, United Arab Emirates (UAE).

Methods: It was cross-sectional descriptive study over a period of six months. Patients who came to our outpatient department with complains of vaginal discharge and itching in reproductive age group were included in this study. Patients characteristics i.e. age, parity, risk factors like diabetes, pregnancy, use of oral contraceptive pills (OCPills) and intrauterine contraceptive device (IUCD) were noted. High vaginal swabs (HVS) were collected and sent for culture. Candida positive cases were noted, and results were analyzed.

Results: A total of 224 high vaginal swabs were collected. Prevalence of vulvovaginal candidiasis was found to be $31.6 \%$. It was found more in 26-30 years age group and multiparous women. Previous history of candidiasis and diabetes were the commonest risk factors. Frequency of C. albicans was more $(76.05 \%)$ than non-albicans candida (23.94\%).

Conclusions: Present study concluded that vulvovaginal candidiasis is more prevalent in reproductive age group females, therefore a routine high vaginal swab culture must be performed in every woman presenting with vaginal discharge and itching for correct diagnosis. Women should be educated on clinical symptoms.
\end{abstract}

Keywords: High vaginal swab (HVS), Intrauterine contraceptive device (IUCD), Oral contraceptive pills (OC pills), Prevalence, Reproductive age, Vulvovaginal candidiasis (VVC)

\section{INTRODUCTION}

Vaginal discharge is the commonest reproductive tract infection in gynaecological outpatient department. Whereas an abnormal discharge there is an altered color, amount, associated with itching/malodour, which is caused by the alteration in the normal vaginal flora. ${ }^{1}$ Vulvovaginal candidiasis refers to a disorder characterized by signs and symptoms of vulvovaginal inflammation in the presence of Candida species. It is the second most common cause of vaginitis symptoms (after bacterial vaginosis) and accounts for approximately onethird of vaginitis cases. ${ }^{2}$ Candida spp. are part of the lower genital tract flora in 20\%-50\% of healthy asymptomatic women. ${ }^{3}$ It occurs in $1-14 \%$ of all women of reproductive age throughout the world. ${ }^{4}$ An estimated $75 \%$ of women will experience at least one episode of vulvovaginal candidiasis during their lifetime. ${ }^{5}$ 
Vulvovaginal candidiasis is an important cause of morbidity in pregnancy which can cause abortion, candida chorioamnionitis, subsequent preterm delivery. It has been associated with considerable direct and indirect economic costs. Vulvovaginal candidiasis is caused by overgrowth of Candida yeast species in the vagina and is characterized by curd-like vaginal discharge, itching, and erythema. ${ }^{6} C$. albicans has been documented to be the major cause of VVC, but the proportion of non-albicans Candida species appears to be increasing in last few decades. Diagnosis of VVC based solely on patient history and genital examination is not possible because of the low specificity of symptoms and signs, since other causes mimic VVC, like leukorrhea and pruritus vulvae. ${ }^{7}$ Therefore, to have a definitive diagnosis of VVC, cultural isolation and identification of Candida spp. are crucial.

The objective of present study is to determine the prevalence of vulvovaginal candidiasis among reproductive age group of pregnant and non-pregnant women, attending our outpatient department, to find out its distribution in different age groups and associated risk factors. It helps us to understand the magnitude of the problem in our region and to implement the necessary treatment modalities.

\section{METHODS}

A cross-sectional descriptive study was done over a period of 6 months from January 2017 to June 2017. The study population was selected from the patients who were attending the outpatient's department of gynecology and obstetrics of Prime Medical Centre, Sharjah, United Arab Emirates (UAE).

The study was conducted on total 224 patients of reproductive age group of 20 to 45 years after informed verbal consent, who came to our clinic with complains of vaginal discharge and itching. The purpose of present study was to determine the prevalence of vulvovaginal candidiasis, its distribution and association with risk factors in our region.

\section{Inclusion criteria}

- All married women of reproductive age group.

\section{Exclusion criteria}

- Unmarried women, menstruating women.

A detailed clinical history was taken from the patients age, parity, symptoms of vaginal discharge, itching and risk factors like diabetes, pregnancy, use of oral contraceptive pill (OC pill), Intrauterine copper device (IUCD) and previous history of candidiasis. Following a complete general examination, per abdomen and pelvic examination was performed. For the diagnosis of vulvovaginal candidiasis high vaginal swab (HVS) were taken under sterile precaution, labelled and sent to laboratory for culture. In candida positive cultures, candida albicans or non albicans species (C. glabrata, $C$. tropicalis, C. krusei) were differentiated and recorded. The results were statistically analyzed to determine prevalence and other factors.

\section{RESULTS}

A total of 224 high vaginal swabs were collected and reported in present study. HVS were analysed for both candida albicans and non albicans candida. Among them $31.69 \%(71 / 224)$ swabs were positive for Candida growth on culture and $68.30 \%(153 / 224)$ were negative for candida growth. So, the prevalence of vulvovaginal candidiasis was found to be $31.69 \%$ (Table 1).

Table 1: Prevalence of Vulvovaginal candidiasis in

\begin{tabular}{|l|l|l|}
\hline Culture & Number of patients & Percentage \\
\hline Positive & 71 & 31.69 \\
\hline Negative & 153 & 68.30 \\
\hline Total & 224 & 100 \\
\hline
\end{tabular}

Culture positive patients' clinical details were analysed, and results were given below (based on age group, parity, and risk factors) The highest number of positive cases were found to be in 26-30 years of age group (39\%) followed by 31-35 years (30\%) and 36-40 years (29\%). Authors found in our observation that after 30 years, age wise prevalence of candidiasis was gradually declining. Lowest number of patients with candidiasis were belonged to the age group of above 40 years (14\%) and lowest number in above 40 years $(14 \%)$ (Table 2).

Table 2: Distribution of vulvovaginal candidiasis among different age groups.

\begin{tabular}{|l|l|l|l|l|l|}
\hline & \multicolumn{2}{|c|}{ Candida } & Negative & Total \\
\cline { 2 - 7 } & $20-25$ & Count \% within age group & $2(22.22 \%)$ & $7(77.78 \%)$ & $9(100 \%)$ \\
\hline \multirow{3}{*}{ Age (Years) } & $26-30$ & Count \% within age group & $34(39.08 \%)$ & $53(60.92 \%)$ & $87(100 \%)$ \\
\cline { 2 - 7 } & $31-35$ & Count \% within age group & $16(30.18 \%)$ & $37(69.82 \%)$ & $53(100 \%)$ \\
\cline { 2 - 7 } & $36-40$ & Count \% within age group & $16(29.62 \%)$ & $38(70.38 \%)$ & $54(100 \%)$ \\
\cline { 2 - 8 } & $>40$ & Count \% within age Group & $3(14.28 \%)$ & $18(85.72 \%)$ & $21(100 \%)$ \\
\hline
\end{tabular}


Prevalence of vulvovaginal candidiasis was found to be high in women who had a parity of more than $2(40 \%)$ and lower in nulliparous (25.4\%) (Table 3).

Table 3: Distribution of vulvovaginal candidiasis based on parity.

\begin{tabular}{|l|l|l|}
\hline Parity & $\begin{array}{l}\text { No. with candida } \\
\text { positive culture } n=71 \\
(\% \text { prevalence) }\end{array}$ & $\begin{array}{l}\text { Total no HVS } \\
\text { culture } \mathbf{n = 2 2 4} \\
(\%)\end{array}$ \\
\hline Nullipara & $14(25.45)$ & $55(24.55)$ \\
\hline 1 & $25(31.25)$ & $80(35.71)$ \\
\hline 2 & $24(34.78)$ & $69(30.80)$ \\
\hline More than 2 & $8(40)$ & $20(8.92)$ \\
\hline
\end{tabular}

Previous candidiasis was the most common risk factor associated with VVC prevalence $(66 \%)$ in this study, followed by diabetes (56\%), IUCD (40\%), OCPill (28\%) and pregnancy (26\%) (Table 4).

Table 4: Association between VVC and risk factors.

\begin{tabular}{|l|l|l|}
\hline Risk factors & $\begin{array}{l}\text { Candida positive } \\
\text { culture n=71 }(\% \\
\text { prevalence) }\end{array}$ & $\begin{array}{l}\text { Total no. of } \\
\text { culture } \\
\text { n=224 }(\%)\end{array}$ \\
\hline OC Pill & $2(28.57)$ & $7(3.12)$ \\
\hline IUCD & $2(40)$ & $5(2.23)$ \\
\hline Diabetes & $13(56.52)$ & $23(10.26)$ \\
\hline $\begin{array}{l}\text { Previous } \\
\text { candidiasis }\end{array}$ & $8(66.66)$ & $12(5.35)$ \\
\hline Pregnancy & $5(26.31)$ & $19(8.48)$ \\
\hline None & $41(25.94)$ & $158(70.53)$ \\
\hline
\end{tabular}

Among the women who came with the symptoms of vaginal itching or vaginal discharge, authors found that few had vaginal erythema or curdy discharge on examination but a majority of women with these positive signs was diagnosed with vulvovaginal candidiasis on high vaginal swab culture.

Table 5: Association of observed clinical signs and diagnosis (positive predictive value) of vulvovaginal candidiasis.

\begin{tabular}{lll}
$\begin{array}{l}\text { Clinical } \\
\text { examination } \\
\text { (Vaginal signs }\end{array}$ & $\begin{array}{l}\text { Laboratory } \\
\text { diagnosis } \\
\text { observed } \\
\text { erythema, curdy } \\
\text { discharge) }\end{array}$ & $\begin{array}{l}\% \text { diagnosed } \\
\text { culth }\end{array}$ \\
\hline 51 & 33 & $64.7 \%$ \\
\hline
\end{tabular}

The positive predictive values of these signs for predicting vulvovaginal candidiasis were high (Table 5).

Among the candida positive culture, C. albicans was the predominant species in both pregnant and non-pregnant patients $(76 \%)$ followed by non-albicans candida $(24 \%)$ (Table 6).
Table 6: Prevalence of $\mathrm{C}$. albicans and non albicans candida.

\begin{tabular}{|l|l|l|l|}
\hline $\begin{array}{l}\text { Species } \\
\text { Candida } \\
\text { albicans }\end{array}$ & 49 & 5 & $54(76.05)$ \\
\hline $\begin{array}{l}\text { Non } \\
\text { albicans } \\
\text { candida }\end{array}$ & 17 & 0 & $17(23.94)$ \\
\hline Total & 66 & 5 & $71(100)$ \\
\hline
\end{tabular}

Candida glabrata was found to be most prevalent species out of non-albicans candida (Table 7).

Table 7: Frequency distribution of candida species in candida positive culture patients.

\begin{tabular}{|l|l|l|}
\hline Candida species & $\begin{array}{l}\text { Number of patients } \\
(\mathrm{N}=71)\end{array}$ & Percentage \\
\hline C. albicans & 54 & 76.05 \\
\hline C. glabrata & 11 & 15.49 \\
\hline C. tropicalis & 5 & 7.04 \\
\hline C. krusei & 1 & 1.40 \\
\hline
\end{tabular}

\section{DISCUSSION}

The prevalence of vulvovaginal candidiasis is difficult to determine because the clinical diagnosis is often based on symptoms and not confirmed by microscopic examination or culture (as many as one-half of clinically diagnosed women may have another condition). ${ }^{8}$ The prevalence rate of vulvovaginal candidiasis in present study correlates very closely with the study done by Kalia $\mathrm{N}$ et al. (31\%). ${ }^{9}$ Studies have reported the prevalence of VVC as $25 \%, 24 \%$ and $18.5 \% .{ }^{10-12}$ The prevalence rate is lower than the study done by EA Ugwa (84.5\%) in North-West Nigeria. ${ }^{13}$ Low socioeconomic status, improper hygiene, less education, and African ethnicity are the probable factors for high prevalence in that area. In surveys, the prevalence of vulvovaginal candidiasis is highest among women in their reproductive years. The prevalence increases with age up to menopause and is higher in African-American women than in other ethnic groups. The disorder is uncommon in postmenopausal women, unless they are taking estrogen therapy. It is also uncommon in prepubertal girls, in whom it is frequently over diagnosed. This study found the highest numbers of VVC were in 26-30 years age group (39.08\%) followed by $31-35$ years with $30.18 \%$, which is almost similar to the study reported by EA Ugwa and Yadav K et al. ${ }^{13,14}$ EA Ugwa reported highest prevalence in 26-35 years age group (53\%). Yadav $\mathrm{K}$ et al, found the highest numbers of VVC were in 21-25 years age group (40.44\%) followed by $26-30$ years with $32.58 \% .^{13,14}$ The age group contains women who are younger and are sexually active have low vaginal defense mechanisms against Candida species. ${ }^{15}$ A $26-35$ years age group women are mostly multiparous and use contraception which also favours candidiasis. In present study women above 40 years age group had least infection. (14\%) Advancement in age, on 
the other hand, reduces the effect of estrogen hormone in women, which could lead to lower infection rates as women advance in age. Most women aged over 40 years are less or not sexually active. In relation to parity, $19.71 \%$ nulliparous women and $80.28 \%$ of multiparous women were positive for candida. This finding may be due to higher sexual activity, poor personal hygiene and more use of contraceptive devices in multiparous women. Previous candidiasis was the most common risk factor associated with VVC prevalence (66\%) in this study, followed by diabetes $(56 \%)$. This study has also shown that VVC is associated with usage of IUCD (40\%) and OCPill (28\%) and pregnancy (26\%). This finding is similar to some studies. Kanagal et al, 2014 highlights $60 \%$ of pregnant women with vaginal candidiasis had risk factors like diabetes, previous candidiasis infection, use of antibiotics, oral contraceptive pills and intra uterine contraceptive devices which was statistically significant. ${ }^{16}$ Study done by EA Ugwa has also shown that VVC is associated with usage of the oral contraceptive pills and intrauterine contraceptive devices( $28.9 \%) .{ }^{13}$ Increased glucose levels in the genital tissue enhance yeast adhesion and growth, and vaginal epithelial cells have a greater propensity to bind to $C$. albicans in women with diabetes than in those without diabetes (Bohannon, 1998). ${ }^{17}$

Vaginal discharge, itching, and erythema, while quite common, were insufficient to diagnose vulvovaginal candidiasis in the absence of laboratory confirmation. Authors found a positive association between having clinically diagnosed and laboratory diagnosed vulvovaginal candidiasis. Positive predictive value was high $64.7 \%$. In the study done by Yadav $\mathrm{K}$ et al, reported the highest number of VVC was observed in those of the respondents who had symptoms of vaginal candidiasis and was found to be statistically significant $(\mathrm{p}=0.001){ }^{14}$ A similar study was conducted by Kanagal et al, 2014 reported $82 \%$ of candida positive women were symptomatic and the remaining $18 \%$ were asymptomatic which was statistically significant $(p<0.01)$, was in accordance with the present study. ${ }^{16}$

Candida albicans was the predominant species in $76 \%$ of patients followed by non albicans in $24 \%$ of patients. $(C$. glabrata $15.49 \%$, C. tropicalis $7.04 \%$, C. krusei $1.40 \%$ ). C. albicans was found to be the single most prevalent species in pregnancy. The results of this study were similar to study done by Yadav $\mathrm{K}$ et al. Among all candida isolates, $C$. albicans was found to be predominant organism to cause candidiasis followed by C. glabarata. $(64 \%$ C. albicans, $36 \%$ non albicans candida). ${ }^{14}$ During pregnancy, which is listed as a risk factor, vagina is more sensitive, and the infections occur significantly more often. The high incidence of vaginitis in pregnant women is related to levels of estrogens, which is in turn considered the primary factor for the observed Vulvovaginal candidiasis was more prevalent in women (Sobel, 2012) Candida albicans is both the most frequent colonizer and responsible for most cases of VVC
(Singh, 2003). ${ }^{5,18}$ Nevertheless, over the last decades there have been reports demonstrating an increment in the frequency of cases caused by non albicans species with Candida glabrata consistently being the leading species (Ray et al., 2007; Ringdahl, 2000). ${ }^{19,20}$

\section{CONCLUSION}

Present study concluded that vulvovaginal candidiasis is more prevalent in reproductive age group women. There was significant association between risk factors like previous candidiasis, diabetes, contraceptive user and pregnancy, therefore routine HVS must be performed in all patients including pregnant for correct diagnosis and treatment. Appropriate treatment should be given to all women to prevent complications associated with VVC. All women should be educated about symptoms and personal hygiene to solve the problem of vulvovaginal candidiasis.

\section{Funding: No funding sources}

Conflict of interest: None declared

Ethical approval: The study was approved by the Institutional Ethics Committee

\section{REFERENCES}

1. Freshwater D, Masiln-Prothero S, Blackwell's Nursing dictionary, Inc Blackwell publishing Ltd $2^{\text {nd }}$ ed; 2005:642.

2. Centers for Disease Control and Prevention. Sexually transmitted diseases treatment guidelines, 2015. Annals Emerg Med. 2015;66(5):526-8.

3. McClelland RS, Richardson BA, Hassan WM, Graham SM, Kiarie J, Baeten JM, et al. Prospective study of vaginal bacterial flora and other risk factors for vulvovaginal candidiasis. J Infect Dis. 2009;199(12):1883-90.

4. Thulkar J, Kriplani A, Agarwal N, Vishnubhatla S. Aetiology and risk factors of recurrent vaginitis and its association with various contraceptive methods. Ind J Med Res. 2010;131(1).

5. Singh SI. Treatment of vulvovaginal candidiasis. Clin Rev CPJ/RPC. 2003;136(9):26-30.

6. Achkar JM, Fries BC. Candida infections of the genitourinary tract. Clinical Microbio Rev. 2010;23(2):253-3.

7. Geiger AM, Foxman B, Sobel JD. Chronic vulvovaginal candidiasis: characteristics of women with Candida albicans, C. glabrata and no Candida. Genitourin Med. 1995;71(5):304-7.

8. Berg AO, Heidrich FE, Fihn SD, Bergman JJ, Wood RW, Stamm WE, et al. Establishing the cause of genitourinary symptoms in women in a family practice: comparison of clinical examination and comprehensive microbiology. JAMA. 1984;251(5):620-5.

9. Kalia N, Singh J, Sharma S, Kamboj SS, Arora H, Kaur M. Prevalence of vulvovaginal infections and species-specific distribution of vulvovaginal 
candidiasis in married women of north india. Int $\mathbf{J}$ Curr Microbiol App Sci. 2015;4(8):253-66.

10. Kwawukume EY, Arhin RA. Vulvovaginitis. In: Kwawukume EY, Emuveyan EE, eds. Comprehensive Gynaecology in the Tropics. $1^{\text {st }}$ ed. Dansoman: Asante and Hittscher Printing Press Limited; 2002:72-74.

11. Mirza NB, Nsanze H, D'Costa LJ, Piot P. Microbiology of vaginal discharge in Nairobi, Kenya. Br J Vener Dis. 1983;59:186-8.

12. Otero L, Palacio V, Carreno F, Mendez FJ, Vazquez F. Vulvovaginal candidiasis in female sex workers. Int J STD AIDS.1998;9(9):526-30.

13. Ugwa EA. Vulvovaginal Candidiasis in Aminu Kano Teaching Hospital, North-West Nigeria: Hospital-Based Epidemiological Study. Annals Med Health Sci Res. 2015;5(4):274-8.

14. Yadav K, Prakash S. Prevalence of vulvovaginal candidiasis in pregnancy. Global J Med Med Sci. 2016;4(1):108-6.

15. Kent HL. Epidemiology of vaginitis. Am J Obstet Gynecol. 1991;165(4):1168-76.

16. Kanagal DV, Vineeth VK, Kundapur R, Shetty H, Rajesh A. Prevalence of vaginal candidiasis in pregnancy among coastal south Indian women. J Womens Health Issues Care. 2014;3(6):2.

17. Akah PA, Nnamani CE, Nnamani PO. Prevalence and treatment outcome of vulvovaginal candidiasis in pregnancy in a rural community in Enugu State, Nigeria. J Med Med Sci. 2010;1(10):447-52.

18. Sobel JD. Epidemiology and pathogenesis of recurrent vulvovaginal candidiasis. Am J Obstet Gynecol. 1985;152(7):924-35.

19. Ray D, Goswami R, Banerjee U, Dadhwal V, Goswami D, Mandal P, et al. Prevalence of Candida glabrata and its response to boric acid vaginal suppositories in comparison with oral fluconazole in patients with diabetes and vulvovaginal candidiasis. Diabetes Care. 2007;30(2):312-7.

20. Ringdahl EN. Treatment of recurrent vulvovaginal candidiasis. Am Family Physician. 2000;61(11):3306-12.

Cite this article as: Salvi M. Prevalence of vulvovaginal candidiasis in females in the reproductive age group. Int J Reprod Contracept Obstet Gynecol 2019;8:647-51. 